\title{
Digital Technology Education Collaborative First Year Progress Report
}

\author{
Dr. Nasser Alaraje, Michigan Technological University \\ Prof. Aleksandr Sergeyev, Michigan Technological University
}

Aleksandr Sergeyev is currently an Associate Professor in the Electrical Engineering Technology program in the School of Technology at Michigan Technological University. Dr. Aleksandr Sergeyev earned his bachelor degree in Electrical Engineering at Moscow University of Electronics and Automation in 1995. He obtained the Master degree in Physics from Michigan Technological University in 2004 and the $\mathrm{PhD}$ degree in Electrical Engineering from Michigan Technological University in 2007. Dr. Aleksandr Sergeyev's research interests include high energy laser propagation through the turbulent atmosphere, developing advanced control algorithms for wavefront sensing and mitigating effects of the turbulent atmosphere, digital inline holography, digital signal processing, and laser spectroscopy. Dr. Sergeyev is a member of ASEE, IEEE, SPIE and is actively involved in promoting engineering education.

\section{Mr. Craig J. Kief, COSMIAC at UNM}

Mr. Craig J. Kief serves as Deputy Director of COSMIAC. Mr. Kief serves as the lead Program Manager for the Air Force Research Laboratory's Cubeflow training program and is a Research Scholar on the faculty at the University of New Mexico. In this capacity, he is responsible for overseeing curriculum and training development, teaching short courses, and coordinating the scheduling and registration of COSMIAC and NSF courses. Mr. Kief has a B.S. and M.S. in Computer Engineering from the University of New Mexico. He has published and taught in the areas of digital and programmable logic, satellite design and in verification and validation of systems. He is also an IEEE senior member.

\section{Mr. Bassam H Matar, Chandler Gilbert Community College}

Mr. Bassam Matar is a "fun and challenging" guy who clearly gets things done and loves his work. He is a 22-year veteran engineering faculty in the Maricopa Community College District. After 11 years of teaching, Bassam built the Engineering Program at Chandler/Gilbert Community College where he still resides. He developed courses, articulated with surrounding universities, led committees, met with industry leaders, organized events, attended conferences, and applied for grants to enhance the program for students. More specifically, his career includes service as PI or Co-PI on seven National Science Foundation funded grants. In addition, he has been a lecturer at Arizona State University for 12 years. All of the effort and collaboration has amounted to a well-established Chandler/Gilbert Engineering Program-the largest in Maricopa district. Recognitions and awards include Motorola Educator of the Year Award, the National Institute for Staff and Organizational Development Award, the 2010 Electronic Engineering Times ACE Award Educator of the Year, and the City of Gilbert Community Excellence Award for Educator of the Year. 


\title{
Digital Technology Education Collaborative First Year Progress Report
}

\begin{abstract}
The electronics world is undergoing a transformation in the underlying technologies used to create new products for the world's consumers. The movement to reconfigurable digital systems using Field Programmable Gate Arrays (FPGAs) and microcontrollers is sweeping the electronics world in the rush to create smaller, faster, and more flexible consumer and industrial devices. Drake State Community College has put together a team of educational partners spanning the country with the background and skills necessary to create a vibrant virtual center. Team members include colleges and universities with a history of reaching out to minority and under-served student populations. Partners on this project have years of successful National Science Foundation project implementations educating and training hundreds of instructors, and introducing thousands of students to advanced technologies. The goal of this project is to offer an unprecedented opportunity to bring America's technicians directly to this cutting edge of reconfigurable electronics technology. This project will substantially update digital logic courses by providing the tools and curricular materials needed to replace the now outdated materials most commonly used. The updated curriculum will greatly enhance competitiveness for community college graduates seeking to enter the job market or undergraduate engineering programs. Secondly, the project will provide colleges with educational equipment up-to-date with current technological solutions. Most importantly, the project will bring new excitement to education by introducing reconfigurable electronics with a new world of possibilities for student projects, such as robot competitions, video game design, embedded systems and more. Finally, the project will develop industry, K-12 and university partnerships to facilitate pathways to careers in the exciting field of reconfigurable electronics for first-generation, minority and other under-served populations, including veterans. In summary, this project will provide the training and educational resources and promote best practices for community college, university, and high school instructors to enable them to teach new hardware technologies to a broad range of students, including those who have not previously had access to this level of training and career choice. This paper will address first year project activities including the Faculty Professional Development workshop on VHDL and FPGA design, the assessment results and the lessons learned, the summer outreach activity happened at partner institutions, and finally, the undergraduate research experience.
\end{abstract}

\section{Introduction}

Programmable Logic Devices in general and FPGA-based re-programmable logic design became more attractive as a design media during the last decade, and as a result, industrial use of FPGA in digital logic design is increasing rapidly. Considering the following technology trend in industry, the need for highly qualified logic designers with FPGA expertise is increasing rapidly. According to the United States Department of Labor, the job outlook is on the rise and will continue to expand for at least the short- to medium-term future [1]. To respond to the industry needs for FPGA design skills, universities are updating their curriculum with courses in hardware description languages and programmable logic design. Although most traditional electrical and computer engineering programs have updated their curriculum to include topics in hardware description language and programmable logic design (FPGA/CPLD), only $19.5 \%$ of 4- 
year and $16.5 \%$ of 2-year electrical and computer engineering technology programs at US academic institutions currently have a curriculum component in hardware description language and programmable logic design [2]. To effectively meet the next generation's workforce needs, the electrical and computer engineering technology curriculum must be current, relevant, and teach technology that is widely used in industry. Responding to this need, two community colleges (Drake State Chandler-Gilbert) and two universities (Michigan Tech University, and University of New Mexico) proposed to utilize highly-qualified academic and industryexperienced resources to develop and implement online and technology-enabled courses and learning projects that will be scaled up to reach significant numbers of diverse instructors and students over a large geographic area. These collaborative efforts will satisfy this critical need for trained instructors and students in the technology of reconfigurable solutions. Additionally, the project will expand and improve the delivery of education and training material, and provide students and workshop participants with the critical skills sought by diverse electronics industries across the United States. Strategic partnerships in key geographic areas will help underrepresented and unemployed populations advance their skills and training to become eligible for high-wage, high-demand positions in reconfigurable electronics systems. The participating community colleges serve large minority populations (Hispanic, Native Americans, and African-American) in the Southwest and Southeast regions of the United States.

To expand their capacities and create a sustainable educational system for developing electronics technicians, partner institutions will be equipped with reconfigurable electronics laboratories dedicated to delivering curriculum, professional development, and outreach activities that will draw high school students into programs to expand the number and diversity of highly-skilled workers for the targeted industries and accelerate the introduction of qualified workers into the pool of skilled technicians needed by electronics firms. This pool of highly-skilled technicians will be built and sustained by strengthening and expanding community college and university partnerships with K-12 systems, affiliate community colleges, and established industry partners. The partnering universities will assist the community college partners in implementing this already successful workforce development model into their local geographic areas, leveraging the impact of ATE funds, expanding the geographic reach of the proposed program, and developing a nationwide model of successful partnership.

\section{Faculty Professional Development Workshop}

HDL, microcontrollers and FPGAs have revolutionized the way digital logic design should be taught and implemented. Traditional ways of teaching logic design using discrete components (e.g., TTL and CMOS) have been replaced by Programmable Logic Devices. Today, a more standard development process is widely used in industry, incorporating HDL as a design entry to describe the digital systems. In the past 20 years electronic devices have gone from thousands of logical gates to millions of logic gates. Similarly, solutions that used to require boards full of electronics are now available through single-chip solutions. The two largest FPGA manufacturers are the Xilinx and the Altera Corporations. The Project team has subject matter experts on all forms of FPGA technology, including system-on-a-chip and embedded processor capability.

It is clear that the old way of teaching digital electronics, with 7400 series logic gate chips, needs to adapt to the influx of new technology. This cost effective path of reconfigurable electronic 
development is not going away. It proves to be the most efficient and adaptable components within every embedded system. For these reasons, industry will continue to employ these tools for years to come. Community college and 4-year technical program graduates must be prepared to work with these devices throughout their career. It is imperative that they receive the proper training on these devices to draw employment opportunities back to this country. By providing a state-of-the-art learning environment, technicians and technologists can become more competitive within the workplace. The project will help community colleges and 2- and 4-year university-based technical programs to update curricula to meet the expectations of industry by supplying qualified technicians and technologists who have extensive hands-on experience with current design tools. By developing a curriculum that includes hands-on re-configurable electronics laboratories, we will be able to provide students in these programs state-of-the-art training tools that match the expectations of industry.

\section{FPGAs}

FPGAs were created approximately 15 years ago by the Xilinx Corporation [3]. Xilinx is still the largest manufacturer of this technology in the world [10]. FPGAs are not only programmed through a traditional schematic fashion, they are also programmed using HDL. HDL is used to describe the behavior of the circuits that are being created. Although HDLs describe nearly all advanced circuits, certain circuits can be automatically synthesized, meaning that HDL code can be rendered from a computer directly into a working design. This is particularly true of "reconfigurable logic," which includes structured

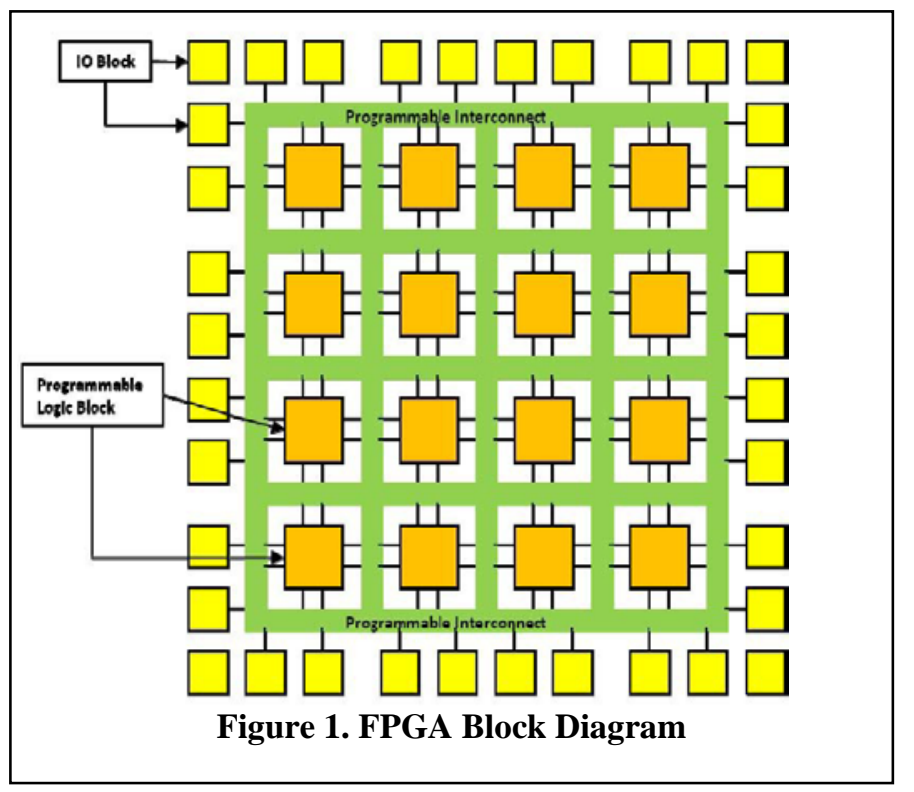
Application Specific Integrated Circuits (ASICs) and the highly versatile FPGA. Many types of FPGAs are reprogrammable, so it is possible for a talented designer to change a digital circuit with instantaneous results. Government and industry have great interest in the many uses of FPGAs; applications range from telecommunications to automotive. Additionally, FPGAs are an ideal teaching tool; they are well-suited as an introduction to the basic digital logic design skills required from today's technician. Inexpensive FPGAs can train students in these exciting digital design concepts while allowing them to rapidly move toward advanced design subjects. All the while, students can be exposed to the latest and most useful techniques that they will encounter in

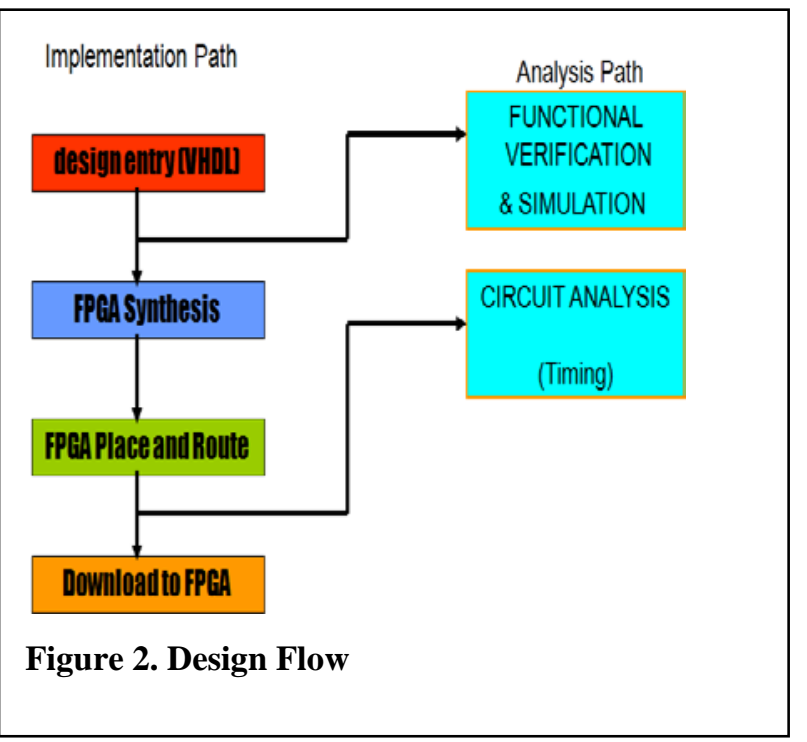


industry upon graduation. FPGAs are rapidly assuming the role of the new "breadboard." They are inexpensive enough ( $\$ 59$ design board; free software) that students can have their own hardware at home.

Figure 1 shows the basic block diagram of an FPGA [11]. The FPGA has two main components. The input and output (I/O) blocks provide formatting and interconnection to the outside world. They handle a wide range of different voltage and data formats. The logic blocks are composed of three basic elements: a look-up table, a D flip-flop and the carry logic. There are hundreds of thousands of these on the even most inexpensive FPGA. Finally, the FPGA contains programmable interconnects that dynamically connect the $\mathrm{I} / \mathrm{O}$ blocks to the programmable logic blocks. There are many ways to design for FPGAs. Figure 2 shows the standard design flow for working with these devices. The hardware and design flow for FPGAs will be explored during both the beginner and advanced workshops offered through this project.

Although FPGAs are only one type of reconfigurable logic,

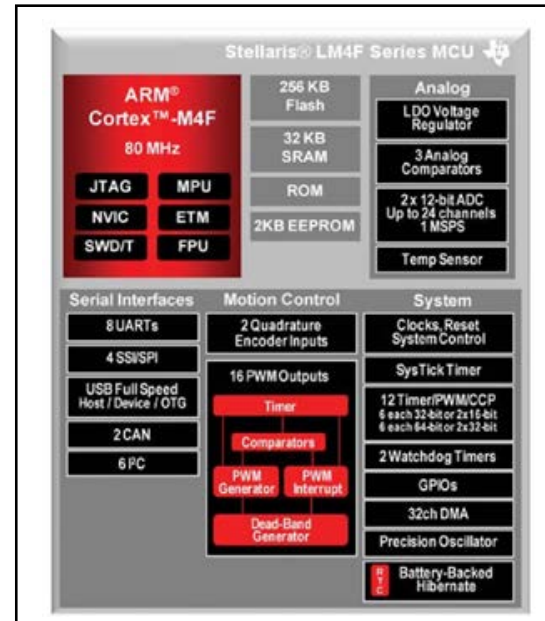

Figure 3. ARM Overview their importance can't be overstated. According to the EE Times [4], "more than 90\% of all ASICs today are either partially or completely prototyped as FPGAs before proceeding to creation of an ASIC.” FPGAs allow companies (large and small) to respond directly to the market with instant gratification in complex advanced circuitry with very low barriers to entry (the design tools introduced in the courses are free). Estimated sales of FPGAs reached $\$ 1.9 \mathrm{~B}$ in 2005, with predictions showing growth of 20\% through 2015 [5]. The demand in the FPGA field alone has created an enormous unsatisfied demand for engineers and technicians skilled in this modern art. Median salaries for FPGA designers with three years of experience are approximately $\$ 90,000$ and technicians with these most modern skills are very rare and command starting salaries of $\$ 50,000$ [6].

Recent research corroborates that the VHDL and FPGA design skills are industry-relevant. In one study, Furtner and Widmer conducted an employer survey to rank currently taught logic design concepts at Purdue University. The survey included questions about many topics that are

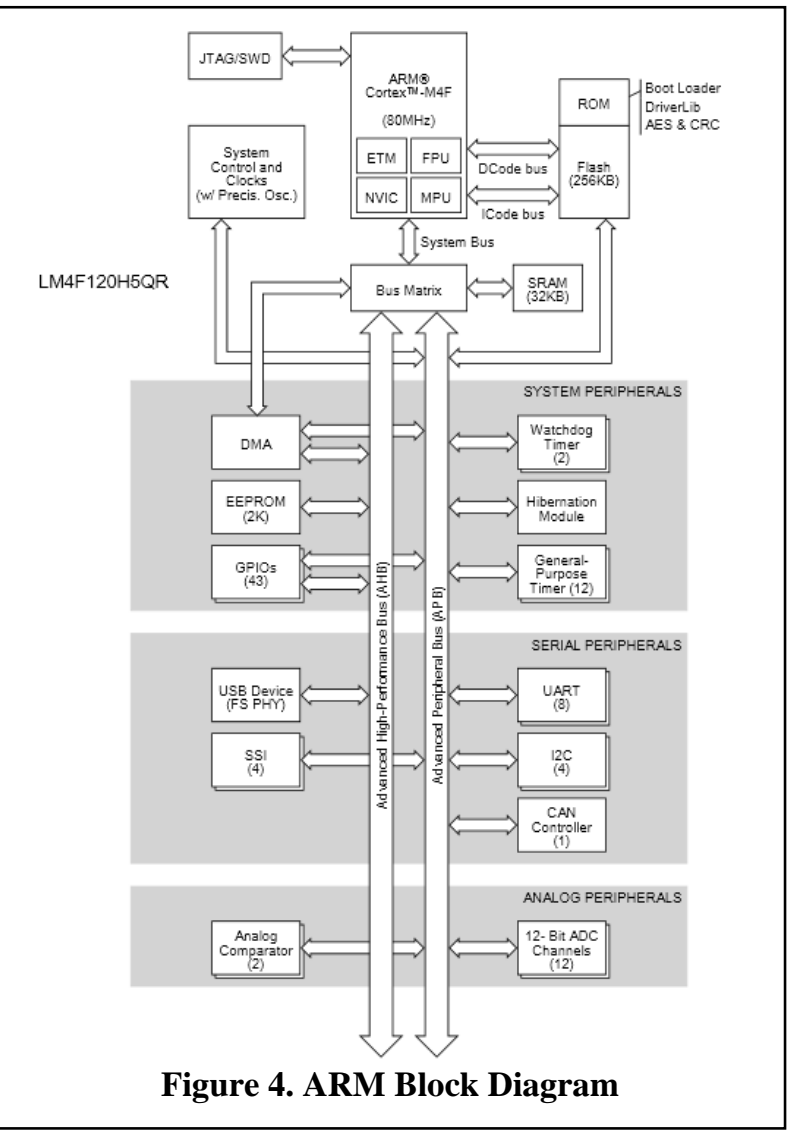
heavily explained in logic design courses such as Boolean algebra, design simplifications using 
K-Maps or Quince-McCluskey, and design implementation using discrete gates. Each was given a low priority from the employer perspective. In contrast, topics covering design with hardware description language (such as VHDL or Verilog) received high-priority rankings [2].

Another very popular form of configurable electronics systems is the microcontroller. Microcontrollers are the 'little brother' to an FPGA. These low-power systems provide a costeffective, simpler alternative to the thousand-pin high performance processing capability of FPGAs - this less-expensive technology can be used to control smaller systems. They are often the device of choice when teaching controls courses as they are easy to understand and less complicated to work with than traditional microprocessors.

\section{Microcontrollers}

Microcontrollers are rapidly becoming one of the most exciting devices in history. The average homeowner of the future will most likely have every aspect of their home designed around them. While an FPGA can serve as a control system, every other device in the home - from lights, home electronics and appliances - will be interfaced through microcontrollers. With these tools, a homeowner will be able to log into their "home" and control every electronic component from the convenience of their handheld device. This same analogy can be applied to cars, businesses and limitless other possibilities through the use of microcontrollers. One microcontroller can manage hundreds of sensors through a single $\mathrm{I}^{2} \mathrm{C}$ bus. A microcontroller is a small computer on a single integrated circuit, containing a processor core, memory, and programmable input/output peripherals, as shown in Figure 3. The microcontroller that the team proposes using for the courses is the TI ARM [7], which is based on an ARM processor. The ARM processor is an industry standard. Isuppli, a well-known market research firm, has confirmed that sales of ARM core processors are currently at 5 billion units per year and sales are predicted to increase as the demand for powerful, low-power electronics also increases [8, 9]. A technician's exposure to and training in this new technology is critical in order to remain competitive in the ever-changing marketplace.

The benefits that microcontrollers have over FPGAs are their small size, low power consumption and analog capability. Figure 4 shows some of these capabilities. Microcontrollers can be mounted into everything from light switches to microwave ovens. Large, complex systems often have an FPGA as the main control system (a hub) and microcontrollers to control individual components (spokes). It isn't necessary for technicians to be experts in all aspects of these two technologies; however, it is crucial for them to have at least a working knowledge of these new systems.

\section{Course Format}

All workshops will be two days in duration. This has proven over the years to be the right amount of time for maximum instructor training without removing instructors from the classroom longer than necessary. All workshops will be taught on Friday and Saturday.

Example of faculty professional development at partner institution was offered at in May 2013. There was an overwhelmingly positive response to the opportunity announced on the Electronics Technology Division (ETD) listserv, which forced the PI to close the registration only two hours following the initial announcement. The faculty workshop was offered at Michigan Tech in May 2013, the project team conducted an intensive, two-day workshop on VHDL and FPGA design. Thirteen Representatives from twelve institutions in ten states (Indiana, Illinois, Virginia, New 
York, California, Ohio, Michigan, North Carolina, Massachusetts, and Texas) engaged in the hands-on learning experience, working with both the software and hardware. The workshop provided faculty members from community colleges and four-year electrical engineering technology programs with the opportunity to expand their expertise in VHDL and FPGA design. The participants will utilize these skills to develop new courses in digital logic design, using VHDL and FPGA, at their respective institutions.

Assessment is a vital part of any curriculum reform project and helps provide useful information for workshop enhancements and determining if the workshop has met its objectives. Formative evaluation occurred during the workshop delivery and will be used to inform adjustments for subsequent workshop offerings. Embedded assessment is used to measure each workshop objective and determine whether goals are met. Assessment of the effectiveness of the faculty workshops training sessions offered is conducted anonymously using pre- and post-surveys. Assessment data collected and analyzed from the workshop will result in continuous improvement actions to be implemented in year two faculty workshop. We use a pre-test/posttest design and pre-survey/post-survey employing both direct and indirect measures of student learning. The indirect assessment instrument also included questions regarding participants' satisfaction while direct assessment instrument include a set small design problems and multiple choices problems.

\section{Direct Measures of Student Learning:}

Participants were given the same instrument for the pre-test and the post-test. The average score on the pre-test was 34\% correct answers. On the post-test, following the instruction, the average score rose to $68 \%$ correct answers. Overall average improvement for this group of students was $34 \%$. It is clear that these participants made substantial progress towards mastering course concepts during the two-day workshop.

\section{Indirect Measures of Student Learning:}

Participants Students were also provided a pre-instruction and post-instruction instrument upon which they indicated their own perception of their level of awareness/proficiency with various aspects of the course before and after the instruction. In addition, on the post-instruction instrument, a series of questions regarding the quality of instruction and student satisfaction were included. On items on a five step Like-type scale with 5 labeled as "Complete Mastery" and 1 labeled as "No Mastery" the following improvement was noted from pre-instruction to postinstruction instruments

\begin{tabular}{|l|l|}
\hline $\begin{array}{l}\text { Quality of Instruction (5= Strongly Agree, 4=Agree, 3=Neutral, 2=Disagree, } \\
\text { 1=Strongly Disagree) } \\
\text { Measurable Outcomes }\end{array}$ & $\begin{array}{l}\text { Post-Test } \\
\text { Overall Rate }\end{array}$ \\
\hline The instruction was clearly presented & 4.54 \\
\hline Any questions I asked were properly answered & 4.77 \\
\hline The materials provided helped me to learn & 4.69 \\
\hline The pace of the course was appropriate for the amount of material to be learned & 3.85 \\
\hline All things taken into consideration, I considered the instruction to be excellent & 4.69 \\
\hline
\end{tabular}

Table 1: Quality of Instruction Participants’ feedback assessment results 


\begin{tabular}{|l|c|c|c|}
\hline Measurable Outcomes (Average Scores) & $\begin{array}{l}\text { Pre-Test } \\
\text { Overall Rate }\end{array}$ & $\begin{array}{l}\text { Post-Test } \\
\text { Overall Rate }\end{array}$ & Change \\
\hline Ability to implement basic constructs of VHDL & 1.77 & 3.77 & +2 \\
\hline Ability to implement modeling structures of VHDL & 1.62 & 3.69 & +2.08 \\
\hline $\begin{array}{l}\text { Ability to use software tools to check the code for } \\
\text { correctness and to correct errors }\end{array}$ & 1.92 & 3.77 & +1.85 \\
\hline Write synthesizable VHDL & 1.92 & 4.15 & +2.23 \\
\hline Control state machine Implementation & 1.85 & 3.77 & +1.92 \\
\hline Optimize a design using operator balancing & 1.62 & 3.85 & +2.23 \\
\hline Create a test bench and run a simulation & 1.69 & 4.23 & +2.54 \\
\hline Create a new Quartus II project & 2.00 & 4.77 & +2.77 \\
\hline Create design components using Megawizard & 1.62 & 4.46 & +2.85 \\
\hline Compile a design and view results & 1.85 & 4.92 & +3.08 \\
\hline Use settings and assignments to control results & 1.69 & 4.62 & +2.92 \\
\hline Make pin assignments and evaluate & 1.77 & 4.62 & +2.85 \\
\hline Use the TimeQuest timing analyzer & 1.46 & 4.48 & +3.00 \\
\hline
\end{tabular}

Table 2: Participants' feedback assessment results

For this two-day workshop, students clearly made substantial improvement in their understanding of course material as measured by both direct and indirect measures. Students were also very satisfied with the quality of instruction. Individual student improvement ranged from $11 \%$ (student had some knowledge of course material before instruction scoring $59 \%$ on the pre-test direct measure) to a 52\% improvement (student scored much more poorly than chance expectations on pre-test direct measure [.07\% correct] and 59\% correct responses after instruction.

\section{Outreach}

The project objective is to increase enrollment in electrical engineering technology programs to create growth in the number of electronics technicians entering the workforce. Partner institutions are addressing its role toward this goal by developing and implementing outreach programs that will not only stimulate greater interest in secondary students seeking electronics technician careers but, also in better preparing secondary students for successful entry into and retention and completion rates in electrical engineering programs at the postsecondary level.

An outreach model has been developed that it expects to result in growth of enrollment in electrical engineering technology programs. The model has three parts: (1) university articulation, (2) high school student outreach, and (3) high school curriculum and teaching enhancement.

\section{Summer Bridge in STEM Subjects for High School Students}

In 2013, 80 local high school juniors and seniors participated in this 64-hour program that integrates mathematics, physics, computer science, and biology into a summer experience in the 
fundamentals of STEM math and science. Students are organized into teams to do projects based on the principles learned during highly interactive classroom sessions. Students perform experiments, document the results of the experiments and perform presentations of their results using Microsoft Word, Excel, and PowerPoint. Students receive college credit for the Alabama Community College course in "Microcomputer Applications" which is transferable as a general education course to any college or university. The program also includes a day-tour of the US Space and Rocket Center, where the students are exposed to a myriad of STEM-related, space and rocket experiments, including hands on exposure to the effects of gravity, velocity, acceleration, and energy in a variety of forms. The program accomplished its goal of reaching and enthusing a significant number of minority and female students.

\section{STEM Camp for Adult Learners}

In 2013, 40 adult learners (recent high school graduates as well as a broad age-spectrum of older adults) participated in a 64-hour program very similar to the High School Summer Bridge. The main difference is that the teaching styles employed are more applicable to the adult learner. These participants, likewise, receive college credit for the Microcomputer Applications course. The adult learners are encouraged to continue their studies in postsecondary STEM programs upon completion of their summer experience.

\section{Enrollment Services}

A new enrollment services management function has been developed utilizing software and successful practices of colleges and universities with similar population demographics, where persistence, retention, and completion issues of first-generation and minority students prevent these students from completion their educational plans. This new function incorporates the Starfish student retention tracking software to expedite the identification of needs for intervention, streamline the communication among faculty members, counselors, academic advisors, and counselors, and provide quantitative and longitudinal data for analysis and summative evaluation of retention initiatives. The Enrollment Services function will integrate outreach, advising, counseling, and student coaching into a seamless service for at-risk students to help them deal effectively with academic and other barriers and thus improve their chances to complete their educational plans.

\section{Ultimate Engineering Experience}

The partner community college hosted a six-week summer program (Intel Ultimate Engineering Experience) for undergrads exploring engineering. The curriculum focuses on building the skills students need in the workplace such as collaboration and critical thinking as well as gaining hands-on engineering experience. To address the shortage of engineers, a number of solutions were introduced to enable students to experience 'real' engineering earlier in their academic careers. The Intel Ultimate Engineering Experience was one of the solution. The goal of the program is to provide underclassman a rich engineering experience, and help them understand what it's like to be an Engineer. The program ran for six weeks with 106 students at the partner community college.

- Week 1 - Entrepreneurship - Students were given a problem and experienced the process of developing a good idea and how to present it. All groups demonstrated what they learned by presenting their idea at the end of the week. All ideas had to include developing an app. 
- Weeks 2 \& 3 - Coding Camp - Students learned basic coding using HTML5. Facilitators mentored students as they developed their app. All groups presented. It was amazing to see what students could do in just a couple of weeks.

- Weeks 4 \& 5 - Robotics - Students were given a robotics kit that is not even available on the market yet. They built, programmed and demonstrated their robot.

- Week 6 - Career Mentorship - Students learned how to market themselves. They experienced defining their personal brand, building a resume, and practicing interviewing.

\section{Conclusion}

Digital systems sit at the heart of the technologies that most enrapture the young. The objectives of this project is to substantially update digital logic courses by providing the tools and curricular materials needed to replace the outdated materials most commonly used. The updated curriculum will greatly enhance competitiveness for community college graduates seeking to enter the job market or undergraduate engineering programs. The objectives of this paper were to present the first year project activities including faculty professional development and outreach activities at partner institutions. This project in its following years will provide the training and educational resources and promote best practices for community college, university, and high school instructors to enable them to teach new hardware technologies to a broad range of students, including those who have not previously had access to this level of training and career choice.

\section{Bibliography}

1. http://www.bls.gov/oco/home.htm.

2. R. Furtner and N. Widmer, "Technology Education and the new frontier of digital electronics," ASEE Annual Conference \& Exposition (ASEE 2006), June 2006

3. N. Alaraje and A. Sergeyev, " Professional Development Opportunity for Electrical Engineering Technology Educators in VHDL and FPGA design " 2012 ASEE Annual Conference \& Exposition Proceedings, San Antonio, Texas.

4. J. Jaeger, “FPGA-based prototyping grows up,” EE times, Dec 2007.

5. Semiconductor logic markets, "FPGA market will reach $\$ 2.75$ billion by decade's end," 2006. [Online]. Available: http://www.instat.com/press.asp?Sku=IN0603187SI\&ID=1674. [Accessed: Aug 25, 2009]

6. www.salaries.com, [Accessed: Aug 27, 2009].

7. The Cypress Corporation 2012. [Online]. Available: http://www.cypress.com/?id=1353. [Accessed: 24 September 2012]

8. ISUPPLI, "ARM Processors to Ship in Nearly One-Quarter of Notebook PCs in 2015", [Online]. Available: http://www.isuppli.com/home-and-consumer-electronics/news/pages/arm-processorsto-ship-in-nearly-one-quarter-of-notebook-pcs-in-2015.aspx. [Accessed: 24 September 2012]

9. Computer Weekly Website. “Chip maker ARM boosts profits by 44\%”. [Online]. Available: http://www.computerweekly.com/news/2240106620/Chip-maker-ARM-boosts-profits-by-44. [Accessed: 24 September 2012]

10. Wikipedia, Xilinx largest market share, [Online]. Available: http://en.wikipedia.org/wiki/Fieldprogrammable_gate_array [Accessed: 07 October, 2013]

11. Spartan-6 Family Documentation Overview, [Online]. Available: hitt:///www.xilinx.com/support/documentation/data_sheets/ds160.pdf [Accessed: 07 October, 2013]

\section{Acknowledgments}

The authors gratefully acknowledge the support for this project under the National Science Foundation - Advanced Technological Education Award No. DUE-1205169. 